\title{
REDESCRIPTION OF SCORPIO KRUGLOVI (BIRULA, 1910) (SCORPIONES, SCORPIONIDAE) FROM THI QAR PROVINCE, SOUTH OF IRAQ
}

\author{
Ghassan A. Ali Al-Yacoub* Murtatha Y. M. Al-Abbad** \\ and \\ Dhia K. Kareem** \\ *Department of Biology, College of Education for Pure Sciences, University \\ of Thi-Qar, Thi-Qar, Iraq. \\ **Department of Biology, College of Education for Pure Sciences, \\ University of Basrah, Basrah, Iraq. \\ -Corresponding author: Ghassanadnanali@gmail.com
}

Received Date: 27 April 202 1, Accepted Date: 10 June 2021, Published Date: 20 June 2021

\section{ABSTRACT}

Information on the scorpions' fauna of Iraq is limited especially in Thi Qar Province. The scorpion specimens of the present study were collected from the desert area which is located between the provinces of Thi Qar and Al-Muthana (Al-Kata'a region). The Scorpio kruglovi (Birula, 1910) redescribed in this study was found in this area.The diagnostic characters are given and the important features are figured.

Keywords: Iraq, Redescription, Scorpio, Scorpionidae, Thi Qar.

\section{INTRODUCTION}

Scorpions in Iraq have not received much attention, as the history of these studies began in the 19th century by Peters (1861), Simon (1880) and Kraepelin (1899). Iraqi researchers did not enter this field until after a long time, as some of them conducted taxonomic studies on scorpions in some areas such as, Khalaf (1962, 1963), Tahir et al. (2014), Al-Azawi (2016) Kachel (2020), Hussen and Ahmed (2020) and Kachel et al. (2021). Speaking of southern of Iraq, there are a few studies dealt with the scorpions.

Al-Azawi (2016) collected specimens from nine provinces in central and southern Iraq, seven genera and eight species including Scorpio maurus (Linnaeus, 1758). While only from Thi Qar Province, Al-Khazali and Yağmur (2019) recorded six species of scorpions.

Kachel (2020) recorded Scorpio maurus (Linnaeus 1758), Androctonus crassicauda (Olivier, 1807) and Hottentotta saulcyi (Simon, 1880) in Zakho (Dohuk Province). Hussen 


\section{Redescription of Scorpio kruglovi}

and Ahmed (2020) published a new data of scorpion fauna, specimens were collected from three provinces (Erbil, Dohuk and Sulaymaniyah) and they were identified as: Scorpio maurus, H. saulcyi, A. crassicauda, Orthochirus fomichevi (Kovařik et al., 2019), Compsobuthus matthiesseni (Birula, 1905), Hemiscorpius lepturus (Peters, 1861), Mesobuthus phillipsii (Pocock, 1889) and Buthacus macrocentrus (Ehrenberg, 1828). The species B. macrocentrus and H. lepturus was identified as a new record in Kurdistan RegionIraq.

Recently, Kachel et al. (2021) published checklist and a review of the scorpion fauna of Iraq (Arachnida: Scorpiones). The review revealed that there are five families (Buthidae, Euscorpiidae, Hemiscorpiidae, Iuridae, and Scorpionidae) including 13 genera and 19 scorpion species. Buthidae alone included nine genera and 15 species; they also corrected record of Orthochirus mesopotamicus (Birula, 1918) into O. iraqus (Kovařík, 2004) which was collected from Thi Qar Province.

Family (Scorpionidae) can be distinguished according the following characters: patella of pedipalp with ventral trichobothria, absence of retrolateral pedal spur, lateroapical margins of tarsi produced into rounded lobes, sternum pentagonal and chelae with a very broad hand (Navidpour et al., 2008). There are clear grooves in the dorsal part of prosoma Scorpio kruglovi, the fixed finger of Chelicerae bears 4 teeth: 2 of them (basal and median), in a fork arrangement, one subdistal and one distal tooth, the movable finger is highly important taxonomically and have 4 dorsal teeth in dorsal view: one distal dorsal tooth, one subdistal tooth, one median tooth and one basal tooth, and in the ventral view of moving fingers, the ventral edge is smooth and toothless and has one large distal ventral tooth. Telotarsus (tarsus) of Scorpio kruglovi has rounded tip and short ventral spines (Stockmann and Ythier, 2010).

The current study aims to redescribe the Scorpio kruglovi which is found in the southern southern Iraq and diagnose it for the first time in Thi Qar Province, and to emphasize that it is the only species present in Iraq from family Scorpionidae.

\section{MATERIALS AND METHODS}

The field survey was conducted during December 2020 to March 2021 in Al-Kata'a region which is located between the Provinces of Thi Qar and Al-Muthana, 31 ${ }^{\circ} 18^{\prime} 47^{\prime \prime}$ N, 45 $54^{\prime} 12^{\prime \prime}$ E, $9 \mathrm{~m}$ a.s.l. The area is a barren desert with sandy soil and is located about $50 \mathrm{~km}$ northern Al-Nasiriyah city center (Map 1). Scorpions were collected during the daytime, after digging the soil and removing rocks. The specimens were placed in a freezer, then were exposed to a hot water to straighten metasoma area and then preserved in $70 \%$ ethanol until being diagnosed under a Krüss stereomicroscope using the identification keys: Kovař́k (1999) and Prendini (2000), Navidpour et al. (2008) and Ahmed (2015).The specimens were photographed with a digital and mobile cameras and finally the images were processed using Microsoft Office 2010 with slight changes in brightness and contrast. 
Al-Yacoub et al.

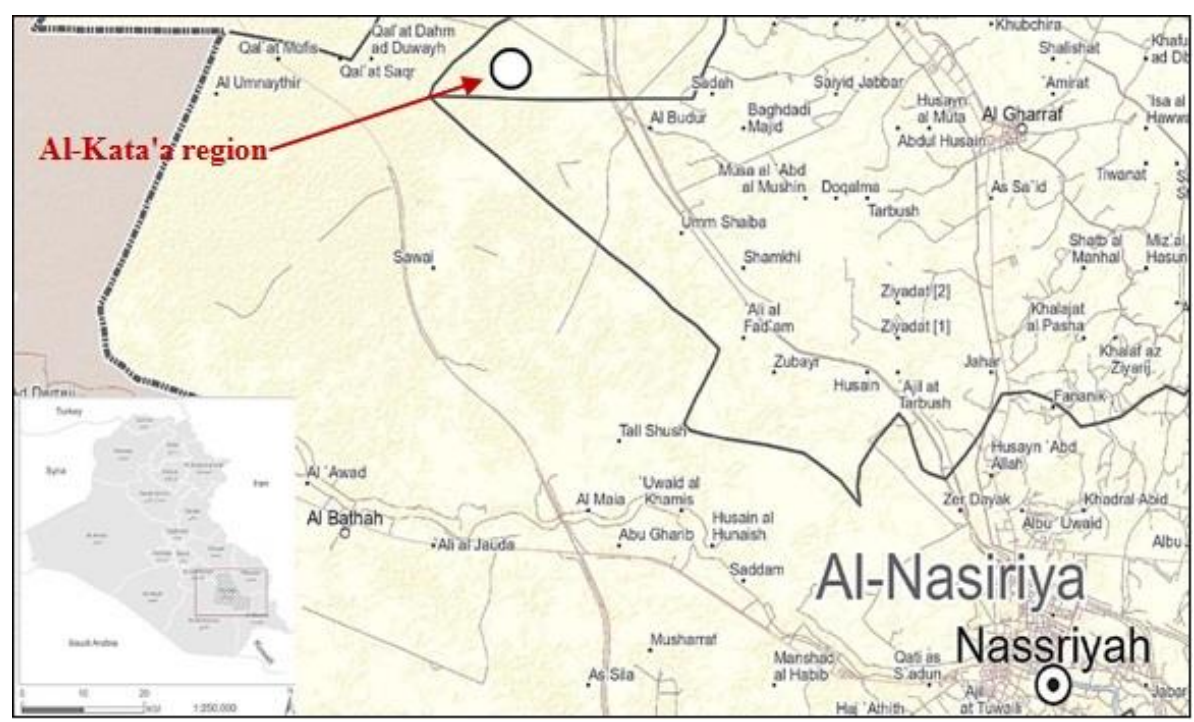

Map (1): Showing sample collection site in Thi Qar province, southern of Iraq (Available at: https://www.humanitarianresponse.info/en/operations/iraq/infographic/iraqthi-qar-governorate-reference-map-2020-en)

\section{RESULTS AND DISCUSSION}

Family: Scorpionidae (latreille, 1802)

Scorpio kruglovi (Birula, 1910)

Synonyms: Scorpio maurus (Linnaeus, 1758)

Type locality and repository: Deir ez-Zor, upper Euphrates, Syria; Zoological Institute, Russian Academy of Sciences, St. Petersburg, Russia (ZISP) (Navidpour, et al., 2019).

Distribution in Iraq: The Genus was previously recorded for the first time from Mosul Province as Scorpio maurus (Penther, 1912 and Khalaf, 1962). Pringle (1960) reported that $S$. maurus is found in Duhok Province, then Al-Azawi (2016) recorded it in Najaf Province also as S. maurus, as well as Kachel (2020) in Zakho Province. While Ahmed (2015) recorded it as a subspecies, Scorpio maurus kruglovi (Birula, 1910) in Erbil Province, Northern Iraq.

Distribution outside Iraq: Kuwait, Saudi Arabia, Iran, Syria, Jordan, Qatar and Turkey (Fet 2000, Navidpour 2019, El-Hennawy 1992 and Talal et al., 2015).

Materials examined: $2 \widehat{\partial}$, Al-Kata'a region (Thi Qar Province), $31^{\circ} 18^{\prime} 47^{\prime \prime} \mathrm{N}, 45^{\circ} 54^{\prime} 12^{\prime \prime} \mathrm{E}, 9$ m a.s.l.

Diagnosis: Sternum pentagonal; patella of pedipalp with 3 ventral trichobothria; femur of pedipalp with three trichobothria, only one of them on the inner surface. Chela of pedipalp with 26 trichobothria, has short and powerful claws, average ratio of length to height of the claw is 1.5 , Manus is very broad, entirely rounded and about as wide as length. Pectin teeth 


\section{Redescription of Scorpio kruglovi}

are short and have a circular inner fulcrum. Lateroapical margins of tarsi produced into rounded lobes and 14 short spines are found on the fourth tarsus.

Description: Total length of male is $27 \mathrm{~mm}$; measurements of the carapace, metasoma, telson and segments of the pedipalps are given in Table (1). The color of the body is brown to dark brown, metasoma III and IV black in the carinae, while segment V is completely black, telson brown and aculeus is reddish black, the anterior margin of carapace is black in color and articular areas of the legs have red spots (Pl. 1). Dorsal trichobothria of femur of pedipalp arrange in $\mathrm{C}$ configuration ( $\mathrm{Pl}$. 2). Patella of pedipalp has three trichobothria ventrally (Pl. 3), and 13 on external surface. Absence of retrolateral pedal spur, lateroapical margins of tarsi produced into rounded lobes (Pl. 4 A, B). The ventral surface of the metasomal segments from I to IV, with 4 carinae (Pl. 5), while V metasomal segment with 3 carinae (Pl. 5).Sternum genital organ has deep sub pentagonal (Pl. 6). 14 pectinal teeth ( $\mathrm{Pl}$. 7). Movable and fixed fingers of pedipalps with 5 rows of horizontal denticles, with 5 rows of vertical denticles extending between them and the end of movable finger with one terminal denticle and 4 subterminal denticles, the end of fixed finger has one terminal denticle and one subterminal granule $(\mathrm{Pl} .8)$.

Kovarík and Affilastro (2013) stated that the species Scorpio maurus contains many subspecies around the world, and Talal et al. (2015) raised S. kruglovi to species level while it was a subspecies as S. maurus kruglovi. While, Al-Khazali and Yağmur (2019) in Thi Qar Province, didn't record species S. kruglovi. Furthermore, Kachel et al. (2021) published a checklist and review for scorpion fauna in Iraq, the review showed that all the previously found subspecies are S. kruglovi, and they identified the areas of their distribution in the provinces of north and central Iraq (Mosul, Erbil, Dohuk, Baghdad and Najaf), and they indicated that this species is not registered in southern Iraq.

The studied traits of this species S. kruglovi in the present study are identical to that described by the previous studies with a slight difference in length, and this may be due to the age of the specimens. This was confirmed by Al-Azawi (2016) who observed the presence of differences in the measurements taken among individuals of the same species, and recorded $S$. maurus with a total length $49.02 \mathrm{~mm}$ and described Chela as being very wide and the body color was golden to yellow. Whereas Kachel (2020) reported that the color was yellowish brown with dark brown in mesosoma. Ahmed (2015) described S. maurus kruglovi which was found in Erbil city- northern of Iraq to be 6-8 cm in length. Hussen and Ahmed (2020) found that most of the specimens were yellow to red brown color, the tip of the claws was dark redbrown, and their length ranged from 30 to $40 \mathrm{~mm}$, with 13-14 pectinal teeth in male. 
Al-Yacoub et al.

Table (1): Measurements of the carapace, metasoma, telson and segments of the pedipalps (Scorpio kruglovi). (Abbreviations: length: L, width: W).

\begin{tabular}{|l|l|}
\hline Parameters & \multicolumn{1}{|c|}{ Measurements (mm) } \\
\hline Carapace & L: $4, W$ W 45 \\
\hline Mesosoma & L: 8 \\
\hline Metasoma + Telson & L: 15 \\
\hline Pedipalp & L: 12 \\
\hline Femur & L: $3.5, W: 1.25$ \\
\hline Patella & L: $4.2, W: 1.5$ \\
\hline Manus & L: $3 /, W: 3$ \\
\hline Movable finger & L: 4.1 \\
\hline
\end{tabular}

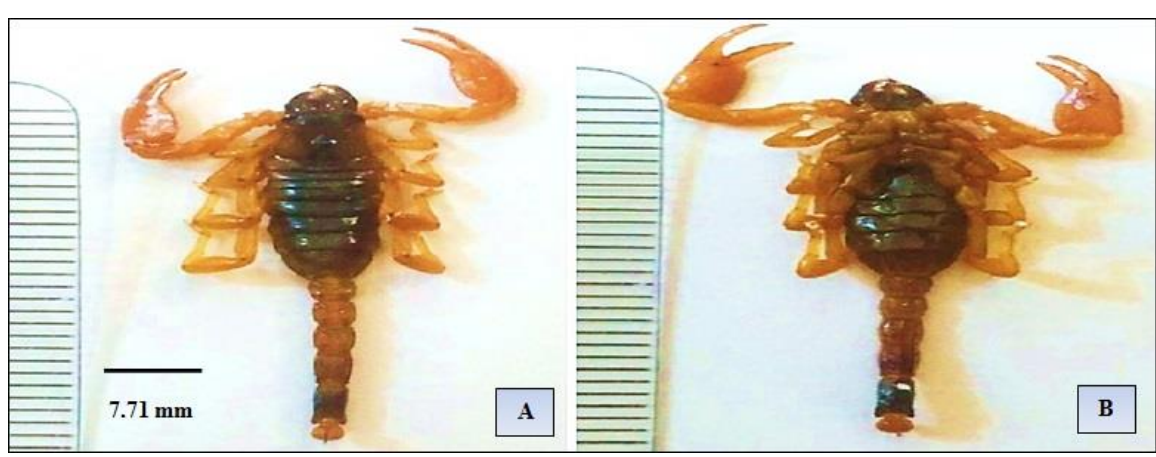

Plate (1): Male Scorpio kruglovi; Dorsal (A) and views ventral (B).

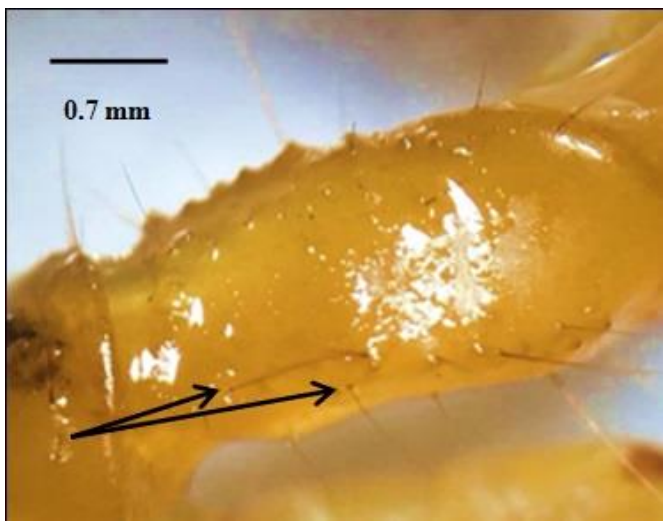

Plate (2): Dorsal trichobothria of pedipalp femur in male. 
Redescription of Scorpio kruglovi

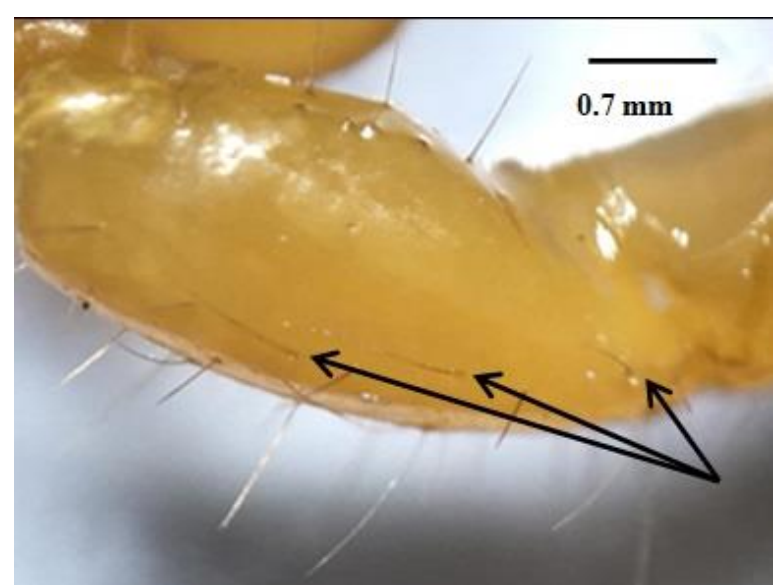

Plate (3): Ventral trichobothria of pedipalp patella in male.

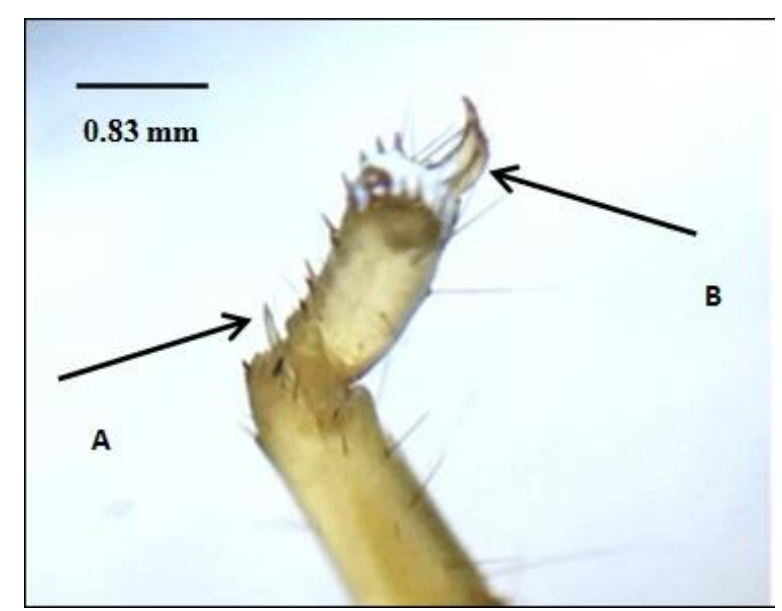

Plate (4): Tarsus of third leg in male (A) pedal spur, (B) Lateroapical margins of tarsi.

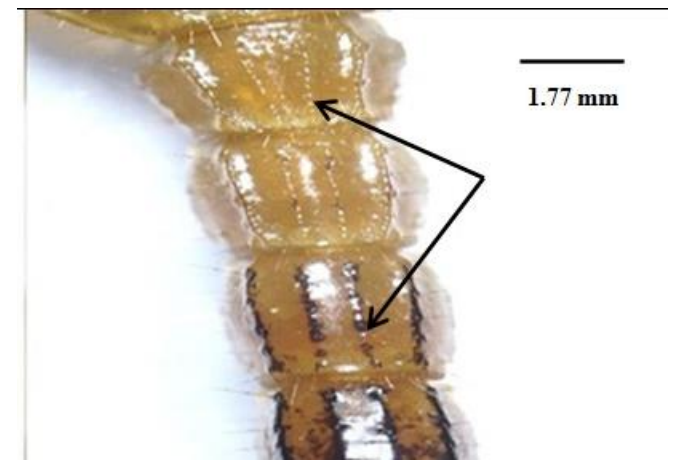

Plate (5): Ventral submedian carinae of metasoma in male. 
Al-Yacoub et al.

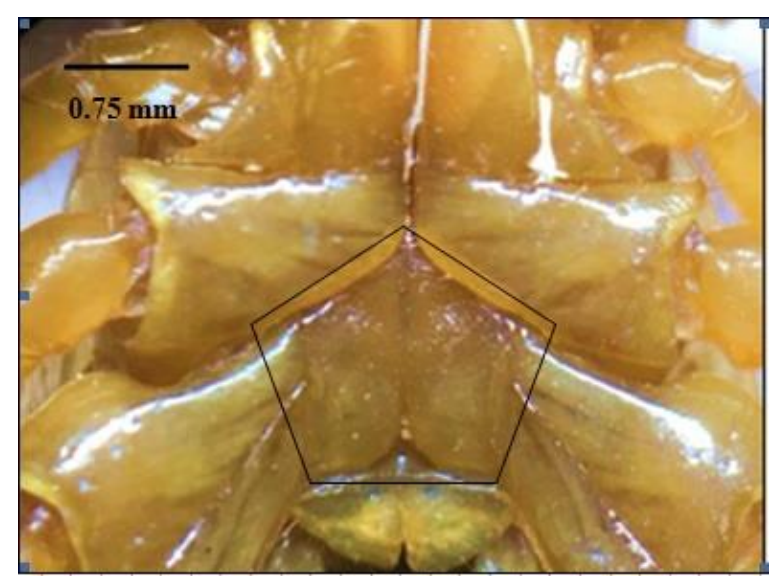

Plate (6): Pentagonal sternum in male.

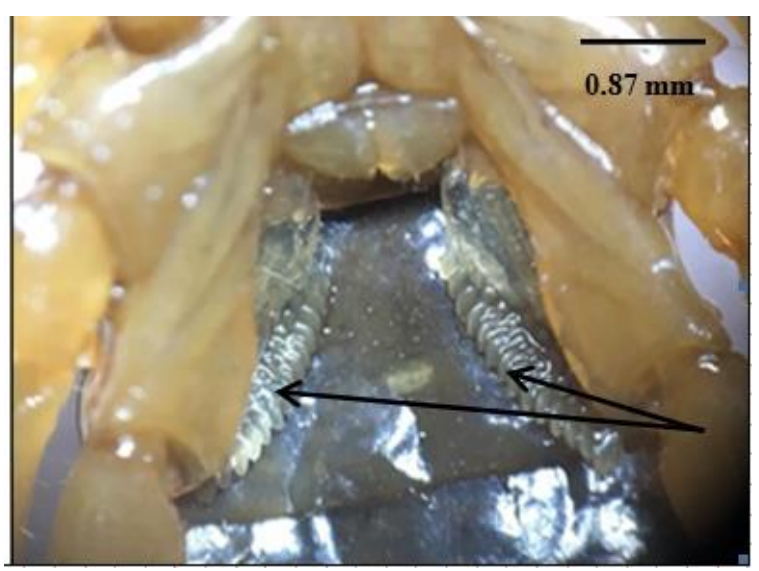

Plate (7):Pectinal teeth in male.

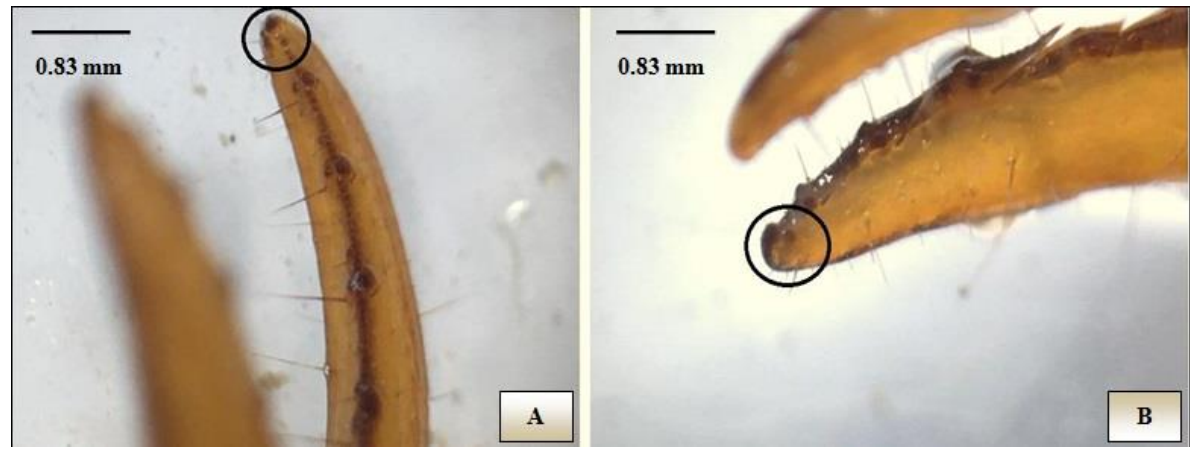

Plate (8): Movable (A) and fixed fingers (B) of pedipalps in male. 


\section{LITERATURE CITED}

Ahmed, S. T. 2015. Morphology and histology of venom gland of Scorpio maurus kruglovi (Birula, 1910) (Scorpionidae: Scorpiones). Zanco Journal of Pure and Applied Sciences, 27(5): 59-62.

Al-Azawi, Z. N. N. 2016. List of scorpions recorded for the first time in Iraq. Ibn Al-Haitham Journal for Pure and Applied Science, 29 (1): 49-57.

Al-Khazali, A. and Yağmur, E. 2019. First record of Androctonus bicolor Ehrenberg, 1828 (Arachnida: Scorpiones) with scorpion records Thi Qar Province, Iraq. Biharean Biologist, 13: 85-88.

El-Hennawy, H. 1992. A catalogue of the scorpions described from the Arab countries (17581990) (Arachnida: Scorpionida). Serket, 2(4): 95-153.

Fet, V. 2000. Family Scorpionidae Latreille, 1802. In: Fet V, Sissom WD, Lowe G and Braunwalder M.E. (eds).Catalog of the scorpions of the world (1758-1998). New York Entomological Society, New York, p. 427-486.

Hussen, F. S. and Ahmed, S. T. 2020. New data of scorpion fauna, include Two new records with identification key of scorpion Species (Arachnida: Scorpiones) in Iraq. Plant Archives, 20 (2): 6711-6725.

Kachel, H. 2020. Scorpion fauna and scorpionism in Zakho Province of Northern Iraq. Commagene Journal of Biology, 4: (1) 22-27.

Kachel, H. S., Al-Khazali, A. M., Hussen, F. S. and Yağmur, E. A. 2021. Checklist and review of the scorpion fauna of Iraq (Arachnida: Scorpiones). Arachnologische Mitteilungen / Arachnology Letters, 61 (1): 1-10.

Khalaf, L. 1962. A small collection of scorpions from Iraq. Bulletin of the Iraq Natural History Institute, 4: 1-3.

Khalaf, K. 1963. Scorpions reported from Iraq. Bulletin of Endemic Diseases (Baghdad), 5: 59-70.

Kovařik, F. 1999. Review of european scorpions, with a key to species. Serket, 6(2): 38-44.

Kovařík, F. and Ojanguren-Affilastro, A. A. 2013. Illustrated Catalog of Scorpions, Part II. Clairon Production, Prague, 400 pp.

Kraepelin, K. 1899. Scorpiones und Pedipalpi. In: Dahl, F. (ed.) Das Tierreich 8. Friedlander und Sohn, Berlin, 265 pp. 
Al-Yacoub et al.

Navidpour, S. 2019. Scorpion fauna (Arachnida, Scorpiones) of Hamadan Province, Iran. Global Journal of Zoology, 4(1): 007-0012.

Navidpour, Sh., Kovarik, F., Soleglad, M. E. and Fet, V. 2008. Scorpiones of Iran (Arachnida, Scorpions), part 1.Khoozestan Province. Euscorpius, 65: 1-41.

Penther, A. 1912. Wissenschaftliche Ergebnisse der Expedition nach Mesopotamien 1910. Scorpiones. Annalen des Kaiserlich-Koniglichen Naturhistorischen Hofmuseums in Wien, 26: 109-116.

Peters, W. 1861. Eine neue Untergattung von Skorpionen: Monatsberichte der Koniglichen Preussischen Akademie der Wissenschaften zu Berlin, 1861: 426-427.

Prendini, L. 2000. Phylogeny and classification of the super family Scorpionidae, Latreilla 1802, (Chelicerata: Scorpiones). An exemplar approach. Cladistics, 16: 1-78.

Pringle, G. 1960. Notes on the Scorpiones of Iraq. Bulletin of Endemic Diseases (Baghdad), 3: 73-87.

Simon, E. 1880. Descriptions de genres et especes de l'ordre des Scorpiones. Annales de la Societe Entomologique de France, 5(10): 377-398.

Stockmann, R. and Ythier, E. 2010. Scorpions of the World. N.A.P. Editions, Verrières-leBuisson, $565 \mathrm{pp}$.

Tahir, H. M., Navidpour, S. and Prendini, L. 2014. First reports of Razianus (Scorpiones: Buthidae) from Iraq and Pakistan, descriptions of two new species, and redescription of Razianus zarudnyi. American Museum Novitates, 3806: 1-26.

Talal, S., Tesler, I., Sivan, J., Ben-Shlomo, R., Tahir, H., Prendini, L., Snir, S. and Gefen, E. 2015. Scorpion speciation in the Holy Land: Multilocus phylogeography corroborates diagnostic differences in morphology and burrowing behavior among Scorpio subspecies and justifies recognition as phylogenetic, ecological and biological species. Molecular Phylogenetics and Evolution, 91: 226-237. 
(2021) 16 (3): 389-398 .

Scorpio kruglovi (Birula, 1910) إعادة وصف النوع (Scorpiones, Scorpionidae)

$$
\text { من محافظة ذي قار،جنوب العراق }
$$

غسان عدنان علي اليعقوب*، مرتضى يوسف مهدي العبادئ خرئ

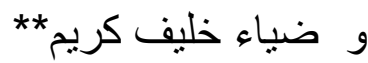

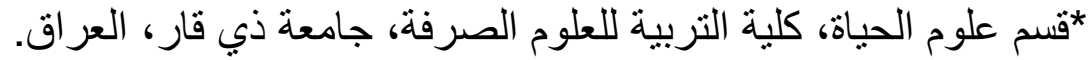

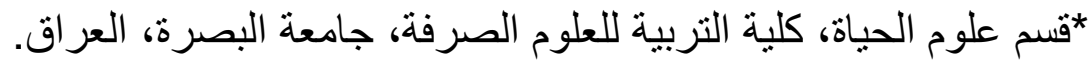

تأريخ الاستلام: 2021/04/27، تأريخ القبول: 2021/06/10، تأريخ النشر: 2021/6/20

$$
\text { الخلاصة }
$$

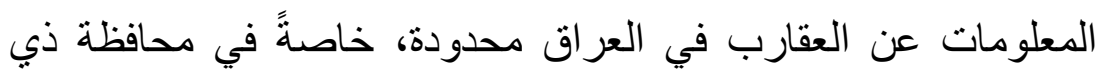

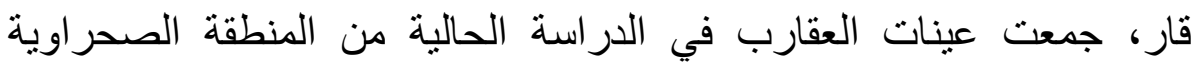
الو اقعة بين محافظتي ذي قار و المثنى (منطقة الكطعة).

أعبد وصف النوع (Birula, 1910) الدنطقة، و دعم بالصفات التشخيصية و تم تحديد الصفات المميزة له. 